\title{
SENSITIVE CENSUS: CHALLENGES AND OPPORTUNITIES IN INDIA'S POPULATION CENSUS SURVEY AND REPORTING
}

\author{
Kanav Aggarwal \\ Modern School Barakhamba Road, New Delhi \\ DOI: 10.46609/IJSSER.2021.v06i03.021 URL: https://doi.org/10.46609/IJSSER.2021.v06i03.021
}

\begin{abstract}
It is acknowledged that the Census remains a vital activity for the development of India, and provides primary data to governments at all levels, researchers, and policy makers. The Census has seen several changes in the past decades, with the expansion of questions to better reflect the demographics and socio economic conditions of the citizens, which is a welcome move. With the implementation of the 2021 Census to begin soon, this paper examines the development and history of the Census and the challenges and opportunities that have arisen. The paper particularly focuses on the recent controversies that have shed light on the issues pertaining to data collection and dissemination, and emphasises the need for engendering of public trust in the data that is collected from them, the security of the data and the protection of their fundamental rights. The paper poses policy recommendations for better implementation and expansion of the Census in 2021 and the upcoming decades.
\end{abstract}

Keywords: Population Census, citizens, urbanization, Migration, digital data

\section{Introduction}

The Census of India has been conducted every decade, and fifteen times as of the year 2011. The next Census will be conducted in the year 2021 which will be the $15^{\text {th }}$ national census of the country. The census is the most high-profile example of information generation and dissemination by a government, and is known as the most important source of information on characteristics of human population (Goswami, 1989). The results of the census that are usually disseminated in the form of printed data volumes are extensively used by planners, policy makers, and researchers (Goswami, 1989). The Census is significant to gather data for several areas and formulate policies for the Central and State Governments, and is referred to by national and international agencies, scholars, business people and researchers (Census Commissioner, n.d). The Census provides primary data on areas such as amenities, urbanisation, fertility and mortality, Scheduled Castes and Scheduled Tribes, language, religion, migration, disability and 


\section{International Journal of Social Science and Economic Research}

ISSN: $2455-8834$

Volume:06, Issue:03 "March 2021"

many other socio-cultural and demographic data since 1872 (Census Commissioner, n.d). The implementation of the census is important to provide data to local governments and governments at all levels in the country, provide a comprehensive source of data, used to be used for administration, governance, planning and policy-making as well as management and evaluation of various programmes run or to be introduced by the Government, NGOs, researchers, commercial and private enterprises, etc (Drishti, 2020).

The 2021 Census will introduce several changes that have not been implemented previously. The 2021 Census will introduce digital data collection via mobile applications, with only a self declaration required by citizens. The Census Monitoring \& Management Portal will act as a single source for all officers/ officials involved in Census activities to provide multi-language support (Drishti, 2020). In addition, the 2021 Census will not collect caste data and for the first time that information of households headed by a person from the transgender community and members living in the family will be collected (Drishti, 2020). The expansion of the Census in this manner is a welcome move. Given the upcoming Census and the new challenges and opportunities brought with it, this paper will examine the history and development of the Census, and the challenges that have been faced and noticed by existing scholarship in the field, and the possibilities and opportunities for bettering data collection and analysis in the future.

\section{Background}

The first Census of India within the modern concept was conducted in 1872 and the next was taken in 1881. Since 1881 a census has been conducted in India every 10 years. Permanent legislation, Census of India Act (Act no. 37 of 1948), empowered the government to establish the date of the census and to appoint a Census Commissioner at centre and Directors of Census Operations in states (Goswami, 1989). The law made it obligatory on the part of the citizen to answer the census questions. The scope and coverage of Indian census have been expanding over the years and the number of volumes disseminating census data have increased enormously (Goswami, 1989). The primary tool of data collection for the Census has historically been the questionnaire method, in which several innovations and changes have been introduced over the decades to reflect the changing socio-economic conditions and demographics of the country, with the introduction of parameters such as school attendance (Goswami, 1989; Drishti, 2020). Historically, the data collection, compilation and analysis has been carried out manually, leading to a large amount of time between the collection of data and the dissemination to the public. However, the 2021 Census aims to address this issue by introducing data collection through a mobile application.

The areas covered by the Census have expanded over the decades. For example, from merely collecting data about the members of a family, the 2021 Census has also been expanded the main 


\section{International Journal of Social Science and Economic Research}

ISSN: $2455-8834$

Volume:06, Issue:03 "March 2021"

source of lighting, whether the family has access to a toilet, waste water outlet, availability of kitchen and LPG or PNG connection and main fuel used for cooking (IAS Gateway, 2020). This will allow for the Census to more accurately reflect the living and economic conditions of the citizens which increases its significance and importance. It is recognised that the Census has importance for utility in administration and policy, for research purposes, for business and industry, as a frame for sample surveys, for use of the data in planning, for the establishment of electoral rolls, among several other important purposes (Insights IAS, 2020). However, despite the recognition of such areas of importance, the Census has seen its challenges with respect to implementation as well as controversies in the recent years. These issues will be examined further in the following section.

\section{Discussion}

There are several challenges that have been observed in conducting the Census, including but not limited to the cost of conducting the Census, inaccurate data collection due to high levels of illiteracy, inadequate infrastructural facilities in certain areas, interference by traditional and religious beliefs, corruption in the census, insufficient census experts, insufficient and ineffective census educational campaign, and poor demographic maps (Insights IAS, 2020). The cost of the 2021 Census is estimated at $\sim 8,754$ crore (and NPR at $\sim 3,941$ crore), involving about 30 lakh enumerators and field functionaries (generally government teachers and those appointed by state governments) (Kapur and Sircar, 2020). Concurrently, the NPR - first prepared in 2010 under the provisions of the Citizenship Act, 1955 and Citizenship Rules, 2003 and subsequently updated in 2015 - will also be updated along with house listing and housing Census (except in Assam) (Kapur and Sircar, 2020). The associated and new challenges posed by the new methods introduced in the 2021 Census are the possibility of errors in the online data collection process, furnishing of false information due to fear of losing intended benefits of various schemes (or fear of losing citizenship with the introduction of the CAA-NPR), and the mistrust and fear of misuse of data collected as well as the lack of assurance as to data security and an adequate backup mechanism (Drishti, 2020). Opponents of the NPR say that the additional questions on parents make the NPR a lethal weapon that will authorise low level administrative officers to mark individuals as doubtful citizens (Patel, 2020). Given that those born after July 1987 will have to offer proof of their parents' citizenship, and some segments of citizens, especially Muslims, are particularly vulnerable to having their citizenship questioned, there will be considerable incentives for people to misreport age, religion and language data (IAS Gateway, 2020).

It is of utmost importance that the implementation of the Census be focused on maintaining unbiased and accurate reporting and the possibilities in expanding the scope of the census in the upcoming decade, and limiting exclusion as much as possible. This includes religion, caste, as well as economic productivity. Considering the example of economic productivity, a recent 


\section{International Journal of Social Science and Economic Research}

ISSN: $2455-8834$

Volume:06, Issue:03 "March 2021"

controversy that has arisen with respect to the watertight categories used to define economic productivity by simply those who make money. However, this excludes the entirety of the informal economy. For example, housewives are excluded simply because they do not earn money without considering that the reason for the same is the perpetuation of patriarchal social stereotypes and that many women are breaking away from this stereotype. Leaving that aside, it is unfair to group the housewives in the same group as beggars and prisoners (Bidani, 2010). The implementation of the Census must look into the creation sub categories that recognise unpaid labour and care labour, most of which continues to be done by women in India. In addition, given that the government recently stated that there is a lack of data on migrant workers who returned to their home states due to the COVID-19 lockdown, activists and academics have called for such data to be included in the Census rather than providing proof of citizenship (Nath, 2020).

Another example of a controversy is the issue that the Census questionnaire does not adequately allow those who identify as atheist to state their lack of a religious affiliation. In the 2001 Census, government enumerators had recorded only 7 lakh people under the "religion not stated" category (Daniyal, 2015). So, rather than any religion being the fastest growing category, it is perhaps the atheists who have grown the most - increasing four times over the decade, at an average annual rate of $15 \%$. Disparities and incongruencies have been noticed with those who are put down under the category of "religion not stated" and the actual demographics of political alliance and atheism in the city or state (Daniyal, 2015). Scholars also argue that what we pass off as religious categories in India - Hindu, Muslim, Sikh, Christian - are actually better thought of as ethnic categories, based more on birth than actual belief, which requires a reconceptualisation of the way in which religion is thought of in the Census (Daniyal, 2015).

Currently, perhaps the largest conversation around the Census rather than the challenges of digital implementation, training or the cost of the Census, is the NPR. Concerned over the linking of National Population Register (NPR) and Census 2021, 190 economists and social scientists have signed a document demanding that both be delinked. Signatories include Maitreesh Ghatak of London School of Economics, S Irfan Habib, Jayati Ghosh of Jawaharlal Nehru University, among others (BS Web Team, 2020). These eminent economists and social scientists said that while Census is an important exercise and helps centre and state governments make and implement welfare schemes effectively, the widespread public distrust on NPR is dangerous (BS Web Team, 2020).

\section{Conclusion}

Concluding from the above observations, it is clear that the 2021 Census will possibly be the most contentious Census to be conducted in Indian history. There is a dire need for the 


\section{International Journal of Social Science and Economic Research}

ISSN: $2455-8834$

Volume:06, Issue:03 "March 2021"

government and policy makers to provide the public with a sense of reassurance and trust with regard to the Census. News reports have showed that data collection exercises such as the National Sample Survey (NSS) are already being hampered in states such as Andhra Pradesh, Karnataka, and West Bengal (Insights IAS, 2020). Reports indicate that people are declining to share personal information with officials in connection with government welfare schemes, with residents turning away ASHA workers on a pulse-polio visit, fearing that their information may be used in the NRC and NPR. Therefore, resolving this issue will be crucial to ease public distrust in the Census process (Insights IAS, 2020). This will be especially important in light of the digital mode of data collection implemented for the first time in the 2021 Census. Such digital collection must necessarily be implemented with capacity building and proper training of enumerators and organisers, as well as strong laws to prevent abuse of data and protect citizens right to privacy and erasure of data once the data has been disseminated for the public to use and view. Minimising coverage and content error will also be crucial in the digital context. As early as 1989 and before the advent of computerisation in the Census process, scholarship has emphasized the need for a user oriented mode of data dissemination and interaction between the user of the data and the statistical agency responsible for the compilation and distribution of the data would be beneficial in determining the content and the form of bibliographical and other auxiliary tools (Goswami, 1989). These issues remain relevant today, and all the more so due to the issues of data manipulation, cyber security, and the possibility of hacking, which underscores the need for training and capacity building to prevent the same, as well as transparency from the government with regard to the use of technology.

The neglect of strategic interactions during enumeration is, in fact, part of a larger problem. While the design of the census tries to minimise the possibilities of manipulation (and of double counting) by simultaneously enumerating the population, it overlooks the fact that this feature also engenders insecurity in a divided society leading to manipulation of data (Kumar, 2019). If the economy is dominated by the state, communities try to secure their future claims on the public goods and services by boosting their numbers in the census and other official record (Kumar, 2019). The only way out of such situations is to build trust in the impartiality of government institutions and facilitate dialogue between communities. Disregarding strategic interactions could open the door for the manipulation of the census, in particular, and of government processes, in general (Kumar, 2019).

\section{References}

Bidani, S, (2010), 'The Problematics of Census in India', Youth Ki Awaaz, https://www.youthkiawaaz.com/2010/07/the-problematics-of-census-in-india/ 
International Journal of Social Science and Economic Research

ISSN: 2455-8834

Volume:06, Issue:03 "March 2021"

BS Web Team, (2020), 'Economists, social scientists call for delinking of Census 2021, NPR', Business Standard, https://www.business-standard.com/article/current-affairs/economists-socialscientists-call-for-delinking-of-census-2021-npr-120030500602_1.html

Census Commissioner, (n.d), 'Why Census is Important?', https://censusindia.gov.in/2011common/why imp.html\#: :text=The\%20Indian\%20Census\%20is\%20the,Disability\%20and\%20 many\%20other\%20socio\%2D

Daniyal, S, (2015), 'People without religion have risen in Census 2011, but atheists have nothing to cheer about', Scroll.in, https://scroll.in/article/753475/people-without-religion-have-risen-incensus-2011-but-atheists-have-nothing-to-cheer-about

Drishti, (2020), 'The Big Picture: Census- Challenges \& Importance', https://www.drishtiias.com/loksabha-rajyasabha-discussions/the-big-picture-census-challengesimportance

Goswami, P.R, (1989), 'The Census of India: A discussion of issues of data collection and dissemination', Government Publications Review, Volume 16, Issue 5, Pages 429-438, ISSN 0277-9390, https://doi.org/10.1016/0277-9390(89)90072-1.

IAS Gateway, (2020), 'Census- Challenges and Importance', https://iasgatewayy.com/censuschallengesimportance/\#: :text=Issues \%20with\%20the\%20Census\%202021\%3A\&text=At\%20its $\% 20$ core $\% 2$ C\%20the\%20fears, choose $\% 20$ to $\% 20$ obfuscate $\% 20$ or\%20misreport.

Insights IAS, (2020), 'RSTV- The Big Picture- Census- Challenges and Importance', https://www.insightsonindia.com/2020/02/15/rstv-the-big-picture-census-challenges-importance/

Kapur, D, and Sircar, N, (2020), 'The new challenge for Census 2021', The Hindustan Times, https://www.hindustantimes.com/analysis/the-new-challenge-for-census-2021/story-

bPNr2SPMGSLp7ofdVMUO7J.html

Kumar, V, (2019), 'The Limitations of India's Census Legislation', Working Paper No.13, Development, Azim Premji University,_https://azimpremjiuniversity.edu.in/SitePages/pdf/APU192312-Working-Paper-Series-13-07.11.2019.pdf

Nath, D, (2020), 'Govt. has no data of migrant workers' death, loss of job', The Hindu, https://www.thehindu.com/news/national/govt-has-no-data-of-migrant-workers-death-loss-ofjob/article32600637.ece 
International Journal of Social Science and Economic Research

ISSN: 2455-8834

Volume:06, Issue:03 "March 2021"

Patel, A, (2020), 'Why India's census is in trouble', The Business Standard, https://www.business-standard.com/article/opinion/why-india-s-census-is-in-trouble120022100050_1.html 